\title{
No effect of familiarity on the Coolidge effect in prairie voles (Microtus ochrogaster)
}

\author{
JOHN D. PIERCE, JR., KIMBERLY K. O'BRIEN, and DONALD A. DEWSBURY \\ University of Florida, Gainesville, Florida
}

\begin{abstract}
The Coolidge effect, the reliable resumption of copulation by a sexually satiated animal following introduction of a new stimulus partner, was studied in prairie voles, a generally monogamous species, in an attempt to assess whether prior familiarity with the second female affects the resumption of copulation. In Experiment 1, satiated males were paired with either the original female, a novel female, or a different, but familiar, female. There were no significant differences in resumption rates or the amount of copulatory activity. In Experiment 2, a more rigorous satiety criterion was imposed. Again, no significant differences were noted in resumption rates or the amount of copulatory activity across conditions. Prior familiarity with a female does not affect the resumption of copulatory activity by satiated male prairie voles.
\end{abstract}

It has been proposed (Dewsbury, 1981a, 1981b) that the Coolidge effect, the reliable resumption of copulation by a sexually satiated animal following introduction of a new stimulus partner (Wilson, Kuehn, \& Beach, 1963), should be characteristic of species that are generally polygamous, whereas generally monogamous species should show no such effect. Studies with muroid rodents have provided general support for this proposal. Thus, species that have demonstrated a Coolidge effect in laboratory tests include laboratory rats (Rattus norvegicus; Brown, 1974; Wilson et al., 1963), rice rats (Oryzomys palastris; Dewsbury, 1970), deer mice (Peromyscus maniculatus; Clemens, 1969), golden hamsters (Mesocricetus auratus; Bunnell, Boland, \& Dewsbury, 1977; Johnston \& Rasmussen, 1984), montane voles (Microtus montanus; Dewsbury, 1973), meadow voles (M. pennsylvanicus; Gray \& Dewsbury, 1975), and Northern grasshopper mice (Onychomys leucogaster; Dewsbury, 1981a). These species appear to be generally polygamous (see Dewsbury, 1981c), with the possible exception of Northern grasshopper mice, which may demonstrate a monogamous system under some circumstances (Dewsbury, 1981c, 1988). To date, satiated males of two species, old-field mice $(P$. polionotus; Dewsbury, 1971) and prairie voles $(M$. ochrogaster; Gray \& Dewsbury, 1973) have not shown a reliable resumption of copulation following introduction of a novel female. It is significant that both of these species appear to be generally monogamous.

The present studies were designed to examine more closely the failure of prairie voles to demonstrate a Coolidge effect. Existing laboratory and field evidence suggests that prairie voles generally display a monoga-

This research was supported by Grant BNS-8904974 from the National Science Foundation. Requests for reprints should be sent to D. A. Dewsbury, Department of Psychology, University of Florida, Gainesville, FL 32611. mous mating system (Carter, Getz, \& Cohen-Parsons, 1986; Dewsbury, 1988). With regard to the Coolidge effect, Gray and Dewsbury (1973) reported that only four of eight satiated prairie vole males resumed copulation following introduction of a novel, previously mated female, compared with five of eight males resuming copulation (with three achieving ejaculation) with the original female. Prior mating by the second female had no apparent effect on the demonstration of a Coolidge effect, as only two of eight satiated males resumed copulation following introduction of a novel, unmated female.

The failure of prairie voles to demonstrate a Coolidge effect may be due, in part, to the unfamiliarity of the novel partner introduced, as familiarity affects aggressive and sexual interactions in this species. Familiarity resulting from copulation produces pair bonding (Carter et al., 1986), establishes mating preferences (Newman \& Halpin, 1988; Shapiro, Austin, Ward, \& Dewsbury, 1986), and reduces aggressive behaviors to the mating partner (Getz, Carter, \& Gavish, 1981). However, familiarity can also be considered in a different sense, namely, as resulting from prior association with an animal. In prairie voles, social familiarity affects pair-bond formation, aggressive behavior (Carter et al., 1986), and estrus induction (Richmond \& Stehn, 1976). It may be that the Coolidge effect is similarly affected by social familiarity. That is, satiated males may be more likely to resume copulation with a socially familiar female as opposed to a novel female. This possibility was addressed in the present studies.

\section{EXPERIMENT 1}

\section{Method \\ Subjects. The subjects were 10 male and 30 female prairie voles born and maintained in the laboratory colonies at the University of Florida. This colony is derived from breeding stock provided by C. S. Carter and L. L. Getz of the University of Illinois in November 1983. All ani- mals were between 150 and 240 days old by the completion of testing and had been pretested through two ejaculatory series at least 10 days}


prior to the start of testing. Prior to testing, the subjects were individually housed in $23 \times 19 \times 13 \mathrm{~cm}$ polycarbonate cages in colony rooms on a reversed 16:8-h light:dark cycle with lights on starting at 20:00 h. Water and Purina Rabbit chow were available ad lib.

Apparatus. Tests were conducted in $48 \times 27 \times 13 \mathrm{~cm}$ clear polycarbonate cages with hardware-cloth lids and corn-cob bedding. Light was provided with $25-\mathrm{W}$ red light bulbs. Data were collected using either an Esterline-Angus operations recorder (for four tests) or a data-collection program with a personal computer for the remaining tests.

Procedure. Each male was tested in each of three sessions in a counterbalanced design. Three days prior to testing, the males were housed on one side of a $48 \times 27 \times 13 \mathrm{~cm}$ clear polycarbonate cage that was partitioned by a wire-mesh screen. Familiarity was then established by housing a female on the opposite side of the barrier from the male. These females were brought into behavioral receptivity at this time by injection of $0.06 \mathrm{mg}$ of estradiol benzoate. On the day of testing, the males were permitted to copulate with an unfamiliar, hormonally induced female until a satiety criterion ( $30 \mathrm{~min}$ without an intromission or $60 \mathrm{~min}$ without ejaculation) was reached. Following male satiation, the female was removed and replaced by (1) the original female, (2) the female previously housed in the divided cage with the male (familiar female condition), or (3) an unfamiliar female with no prior contact with the male (novel female condition). Pairs were then observed for $30 \mathrm{~min}$ or until the occurrence of an ejaculation.

Measures. The basic copulatory pattern of prairie voles consists of three classes of behaviors: mounts (no vaginal insertion), intromissions (mounts with insertion and thrusting but no ejaculation), and ejaculations (mounts with intromission, thrusting, and seminal emission). The following measures of copulatory behavior were used: intromission latency (IL), time in seconds from the introduction of the second test female until the first intromission; ejaculation latency (EL), time in seconds from the first intromission of a series until ejaculation; intromission frequency (IF), the number of intromissions in a series; thrust frequency (TF), the number of thrusts in a series; and mount frequency (MF), the number of mounts in a series. Two general indices of copulatory behavior were derived from these measures: total copulatory activity $(\mathrm{IF}+\mathrm{TF}+\mathrm{MF})$ and time to ejaculation, the total time from introduction of the second female to ejaculation (IL $+\mathrm{EL}$ ).

\section{Results and Discussion}

Of 10 males, 9 resumed copulation and achieved ejaculation with the novel female, 7 resumed copulation and achieved ejaculation with the familiar female, and 9 resumed copulation ( 7 achieved ejaculation) with the original female. There were no differences across conditions for any measures of copulatory activity or time to ejaculation (see Table 1), with one exception: ejaculation la- tencies were significantly shorter with novel and familiar females than with original females.

The results suggest that males were not fully satiated, as the majority of males resumed copulation quickly in all conditions. This finding was unexpected. The satiety criterion of $30 \mathrm{~min}$ without an intromission or $60 \mathrm{~min}$ without an ejaculation has been used in our laboratory in numerous studies with numerous rodent species (see Pierce et al., 1988) and provides a consistent, albeit arbitrary, termination point. In previous work, prairie vole sexual behavior past the termination point established by the satiety criterion was examined (Pierce et al., 1988). The 14 male-female pairs showed a general decrease in copulatory activity with a lengthening of postejaculatory intervals as observation continued through $24 \mathrm{~h}$. It is important to note that the occurrence of the first ejaculation after the limit set by the satiety criterion took, on average, 69.7 min beyond "satiety." By contrast, the males in the present study took, on average, only $11.9 \mathrm{~min}$ to achieve ejaculation following introduction of the second female. The quicker latencies to copulatory behavior and ejaculation suggest that these males may not have been fully satiated. Accordingly, in Experiment 2, a more rigorous satiety criterion was used.

\section{EXPERIMENT 2}

\section{Method}

Ten sexually experienced male prairie voles were tested in each of three sessions, using a more rigorous satiety criterion: pairs were observed for the first ejaculation and then allowed $2 \mathrm{~h}$ of undisturbed copulation before being observed to a satiety criterion of $30 \mathrm{~min}$ without an intromission or $60 \mathrm{~min}$ without an ejaculation. Procedures were otherwise similar to those in Experiment 1.

\section{Results}

Only 3 of 10 males achieved ejaculation (4 resumed copulation) following reintroduction of the original female, compared with 7 of 10 males achieving ejaculation with the novel and the familiar females, a difference that fell short of statistical significance (Cochran's $Q=3.56$, $p<.17)$. There were no significant differences in copulatory activity across the three groups (see Table 2).

Table 1

Measures of Copulatory Behavior as a Function of Condition for Satiated Males $(N=10)$ in Experiment 1

\begin{tabular}{|c|c|c|c|c|c|c|c|c|}
\hline \multirow[b]{2}{*}{ Measure } & \multicolumn{2}{|c|}{ Original Female } & \multicolumn{2}{|c|}{ Familiar Female } & \multicolumn{2}{|c|}{ Novel Female } & \multicolumn{2}{|c|}{ Friedman } \\
\hline & $M$ & $S E M$ & $M$ & $S E M$ & $M$ & $S E M$ & ANOVA & $p$ \\
\hline \multicolumn{9}{|c|}{ Copulatory Activity } \\
\hline MF & 8.6 & 2.5 & 3.1 & 1.1 & 3.5 & 1.6 & 4.05 & .13 \\
\hline IF & 10.4 & 2.2 & 6.0 & 1.1 & 4.1 & 1.6 & 4.05 & .13 \\
\hline TF & 32.8 & 7.8 & 27.5 & 4.2 & 19.3 & 5.3 & 3.20 & .20 \\
\hline Total & 51.8 & 11.1 & 36.6 & 5.9 & 26.9 & 8.0 & 4.85 & .089 \\
\hline \multicolumn{9}{|c|}{ Time to Ejaculation (sec) } \\
\hline IL & 459.5 & 167.4 & 398.7 & 186.5 & 663.6 & 248.7 & 0.35 & .84 \\
\hline EL & 438.2 & 193.4 & 105.0 & 15.2 & 68.9 & 20.5 & 7.85 & .02 \\
\hline Total & 897.7 & 212.7 & 503.7 & 178.9 & 732.5 & 234.0 & 1.85 & .40 \\
\hline
\end{tabular}

Note-MF $=$ mount frequency, IF $=$ intromission frequency, $\mathrm{TF}=$ thrust frequency, $\mathrm{IL}=$ intromission latency, $\mathrm{EL}=$ ejaculation latency. 
Table 2

Measures of Copulatory Behavior as a Function of Condition for Satiated Males $(N=10)$ in Experiment 2

\begin{tabular}{|c|c|c|c|c|c|c|c|c|}
\hline \multirow[b]{2}{*}{ Measure } & \multicolumn{2}{|c|}{ Original Female } & \multicolumn{2}{|c|}{ Familiar Female } & \multicolumn{2}{|c|}{ Novel Female } & \multicolumn{2}{|c|}{ Friedman } \\
\hline & $M$ & $S E M$ & $\boldsymbol{M}$ & SEM & $M$ & $S E M$ & ANOVA & $p$ \\
\hline \multicolumn{9}{|c|}{ Copulatory Activity } \\
\hline $\begin{array}{l}\text { MF } \\
\text { IF } \\
\text { TF }\end{array}$ & $\begin{array}{l}4.6 \\
1.9 \\
9.2\end{array}$ & $\begin{array}{l}2.5 \\
1.1 \\
5.0\end{array}$ & $\begin{array}{r}5.1 \\
5.0 \\
27.0\end{array}$ & $\begin{array}{l}2.0 \\
1.5 \\
7.8\end{array}$ & $\begin{array}{r}6.8 \\
6.4 \\
28.3\end{array}$ & $\begin{array}{l}3.5 \\
2.3 \\
8.3\end{array}$ & $\begin{array}{l}0.60 \\
2.40 \\
3.35\end{array}$ & $\begin{array}{l}.74 \\
.30 \\
.19\end{array}$ \\
\hline Total & 15.7 & 7.5 & 37.1 & 10.8 & 41.5 & 11.8 & 3.05 & .22 \\
\hline \multicolumn{9}{|c|}{ Time to Ejaculation (sec) } \\
\hline $\begin{array}{l}\text { IL } \\
\text { EL }\end{array}$ & $\begin{array}{r}1242.2 \\
192.9\end{array}$ & $\begin{array}{l}234.7 \\
150.8\end{array}$ & $\begin{array}{l}832.0 \\
125.2\end{array}$ & $\begin{array}{r}243.5 \\
44.6\end{array}$ & $\begin{array}{l}628.5 \\
132.5\end{array}$ & $\begin{array}{r}256.2 \\
40.9\end{array}$ & $\begin{array}{l}2.15 \\
2.45\end{array}$ & $\begin{array}{l}.34 \\
.29\end{array}$ \\
\hline Total & 1435.1 & 196.5 & 957.2 & 232.4 & 760.9 & 227.9 & 1.85 & .40 \\
\hline
\end{tabular}

Note-MF $=$ mount frequency, IF $=$ intromission frequency, $\mathrm{TF}=$ thrust frequency, $\mathrm{IL}=$ intromission latency, $\mathrm{EL}=$ ejaculation latency.

Data from the novel female and the familiar female conditions were then combined for a comparison of reintroduction of the original female versus introduction of a new (either novel or familiar) female. The males displayed more mounts, thrusts, and intromissions $[M(S E)=39.3$ (8.00) vs. 15.7 (7.5); Wilcoxon $Z=1.99, p<.05]$ and achieved ejaculation more quickly with new females $[M$ $(S E)=859.1(113.3)$ vs. 1435.1 (196.5); Wilcoxon $Z=$ $1.89, p<.059$ ] than with the original females.

\section{DISCUSSION}

Consistent with previous research, male prairie voles failed to show a Coolidge effect, regardless of whether the second female was novel or socially familiar. The number of males that resumed copulation and achieved ejaculation with new females was not statistically different from the number of males achieving ejaculation with the original female, although there was a trend in that direction.

Overall, satiated males in Experiment 2 copulated more and showed a quicker resumption of copulation to ejaculation with new (either novel or familiar) versus original females. This result may be due to differences in female receptivity, as the original female may have been less receptive following copulation. Furthermore, the accumulation of material in the reproductive tract may have made copulation and ejaculation more difficult for males in this condition. In previous work with other species, prior mating by the second female has affected resumption rates in some experiments (e.g., Dewsbury, 1973, 1981a; Fowler \& Whalen, 1961) but not others (e.g., Clemens, 1969; Gray \& Dewsbury, 1975; Johnston \& Rasmussen, 1984; Wilson et al., 1963). Gray and Dewsbury (1973) reported no effect of prior mating on the Coolidge effect in prairie voles.

To a certain extent, the failure to obtain a significant difference in the number of males achieving ejaculation with each female may represent difficulty in establishing an adequate baseline for comparison. Traditionally, the control comparison for the Coolidge effect has involved removal and then reintroduction of the original female. Given that prairie voles establish pair bonds (Carter et al., 1986), female departure following copulation is probably unlikely in naturalistic situations. Resumption of copulation with the original female following reintroduction may function as either a form of mate guarding or as serving to reestablish the pair bond, as has been suggested for other monogamous species (Sever \& Mendelssohn, 1988). As such, members of monogamous species might be expected to show reliable resumption of copulation with the original female, as was observed in our Experiment 1 and by Gray and Dewsbury (1973).

This difficulty in establishing a baseline may not be limited to studies involving monogamous species. Males of polygamous species may also resume copulating with the original female as a form of mate guarding. For example, Dewsbury (1981b) noted that the data from Coolidge-effect studies with rats "reveal a range of $0 \%$ to $65 \%$ of males attaining ejaculations with the original females" (p. 470) following attainment of a satiety criterion. Studies with other polygamous muroid rodents show similar rates of resumption. The Coolidge effect, then, entails establishing a substantial rate of resumption relative to what may be a considerable baseline rate.

The more general issue concerns what constitutes sexual satiation, an important component of most models of sexual behavior (Beach, 1956; Sachs \& Barfield, 1976). Sexual satiety is typically defined as a given amount of time without the initiation or completion of an ejaculatory series. It has been argued (Carter et al., 1986) that traditional satiety criteria exclude a great deal of sexual activity from observation and thus underestimate a pair's capacity for copulation. The present results underscore the fact that there is copulatory behavior beyond the termination point established by traditional satiety criteria (see Carter et al., 1986; Pierce et al., 1988; Whalen, 1963), an issue especially critical in Coolidge-effect studies designed to investigate the behavior of satiated males.

\section{REFERENCES}

Beach, F. A. (1956). Characteristics of masculine "sex drive." Nebraska Symposium on Motivation, 4, 1-32.

Brown, R. E. (1974). Sexual arousal, the Coolidge effect and dominance in the rat (Rattus norvegicus). Animal Behaviour, 22, 634-637.

Bunnell, B. N., Boland, B. D., \& DewsBury, D. A. (1977). Copulatory behavior of golden hamsters (Mesocricetus auratus). Behaviour, 61, 180-206.

Carter, C. S., Getz, L. L., \& Cohen-Parsons, M. (1986). Relationships between social organization and behavioral endocrinology in a monogamous mammal. Advances in the Study of Behavior, 16, 109-145.

Clemens, L. G. (1969). Experimental analysis of sexual behavior of the deermouse, Peromyscus maniculatus gambeli. Behaviour, 34, 267-285.

DewsBury, D. A. (1970). Copulatory behavior of rice rats (Oryzomys palustris). Animal Behaviour, 18, 266-275.

DewsBury, D. A. (1971). Copulatory behavior of old-field mice (Peromyscus polionotus subgriseus). Animal Behaviour, 19, 192-204.

DEWSBURY, D. A. (1973). Copulatory behavior of montane voles (Microtus montanus). Behaviour, 44, 186-202.

Dewsbury, D. A. (1981a). The Coolidge effect in northern grasshopper mice (Onychomys leucogaster). Southwestern Naturalist, 26, 193-197.

DEWSBURY, D. A. (1981b). Effects of novelty on copulatory behavior: The Coolidge effect and related phenomena. Psychological Bulletin, 89, 464-482. 
Dewsbury, D. A. (1981c). An exercise in the prediction of monogamy in the field from laboratory data on 42 species of muroid rodents. Biologist, 63, 138-162.

DEWSBURY, D. A. (1988). The comparative psychology of monogamy. In D. W. Leger (Ed.), Comparative perspectives in modern psychology, Proceedings of the Nebraska Symposium on Motivation (Vol. 35, pp. 1-50). Lincoln: University of Nebraska Press.

Fowler, H., \& WhaleN, R. E. (1961). Variation in incentive stimulus and sexual behavior in the male rat. Journal of Comparative and Physiological Psychology, 54, 68-71.

Getz, L. L., Carter, C. S., \& Gavish, L. (1981). The mating system of the prairie vole, Microtus ochrogaster: Field and laboratory evidence for pair-bonding. Behavioral Ecology \& Sociobiology, 8, 189-194.

Gray, G. D., \& Dewsbury, D. A. (1973). A quantitative description of copulatory behavior in prairie voles (Microtus ochrogaster). Brain, Behavior \& Evolution, 8, 437-452.

Gray, G. D., \& Dewsbury, D. A. (1975). A quantitative description of copulatory behavior in meadow voles (Microtus pennsylvanicus). Animal Behaviour, 23, 261-267.

JOHNSTON, R. E., \& RASMUSSEN, K. (1984). Individual recognition of female hamsters by males: Role'of chemical cues and of the olfactory and vomeronasal systems. Physiology \& Behavior, 33, 95-104.

NeWman, K. S., \& HalPIN; Z. T. (1988). Individual odours and mate recognition in the prairie vole, Microtus ochrogaster. Animal Behaviour, 36, 1779-1787.
Pierce, J. D., Jr., Bryan, J. C., Deter, D., Ferguson, B., Sawrey, D. K., TAYlor, S. A., \& Dewsbury, D. A. (1988). Sexual activity and satiety over an extended observation period in prairie voles (Microtus ochrogaster). Journal of Comparative Psychology, 102, 306-311.

Richmond, M., \& STEHN, R. (1976). Olfaction and reproductive behavior in microtine rodents. In R. L. Dity (Ed.), Mammalian olfaction, reproductive processes, and behavior (pp. 197-217). New York: Academic Press.

SACHS, B. D., \& BARFIELD, R. J. (1976). Functional analysis of masculine copulatory behavior in the rat. Advances in the Study of Behavior, 7, 91-154.

Sever, Z., \& Mendelssohn, H. (1988). Copulation as a possible mechanism to maintain monogamy in porcupines, Hystrix indica. Animal Behaviour, 36, 1541-1542.

Shapiro, L. E., Austin, D., Ward, S. E., \& Dewsbury, D. A. (1986). Familiarity and female mate choice in two species of voles (Microtus ochrogaster and M. montanus). Behavioral Ecology \& Sociobiology, 18, 267-274.

WHALEN, R. E. (1963). Sexual behavior of cats. Behaviour, 20, 321-342.

Wilson, J. R., Kuehn, R. E., \& BeACH, F. A. (1963). Modification in the sexual behavior of male rats produced by changing the stimulus female. Journal of Comparative \& Physiological Psychology, 56, 636-644.

(Manuscript received March 13, 1992.) 